\title{
Congenital spinal cord haemangioblastoma: another cause of spinal cord section syndrome in the newborn
}

\author{
M ROIG,* M BALlESCA,${ }^{*}$ C NAVARRO,$\dagger$ A ORTEGA, $\dagger$ R MARTORELL,* \\ A FINA*
}

From the Department of Paediatrics, ${ }^{*}$ and Division of Neuropathology, $\dagger$ Facultad Autonoma de Barcelona, Hospital Infantil, Barcelona, Spain

SUMMARY A newborn infant with negative perinatal history and characteristic clinical findings of upper cervical spinal cord section is described. Metrizamide myelography performed on the 7 th and 22nd days of life was negative. Peroneal somatosensory evoked responses showed a conduction block at the cervical level. Necropsy revealed a haemangioblastoma extending from levels $\mathrm{C} 1$ to $\mathrm{C} 5$.

Since first described by Parrot in $1870,{ }^{1}$ the aetiology of spinal cord section syndrome (SCSS) in the neonate has been almost always associated with trauma during delivery. ${ }^{23}$ Better obstetric care and particularly the practice of prophylactic Caesarean sections in difficult cases with breech presentation has led to a decline in the number of birth injuries. However, the incidence of SCSS has not decreased proportionally, and factors other than birth trauma have proved to be responsible in some cases. ${ }^{45}$

We present the necropsy findings of a spinal haemangioblastoma in a newborn with upper cervical SCSS, which to our knowledge has not been reported previously.

\section{Case report}

A 3,440 g newborn female was referred to us with the diagnosis of severe perinatal asphyxia. She was the product of a first, uncomplicated, 40-week pregnancy of a healthy young unrelated couple. There was no maternal history during pregnancy of viral infection, drug or alcohol ingestion, trauma or exposure to X-rays. Fetal movements were noticed by the mother from the 4th month of gestation. The amniotic membrane ruptured 10 hours prior to delivery: amniotic fluid was clear and no other signs of fetal distress were detected at that time. Delivery was vaginal with cephalic presentation and forceps extraction. Despite appropriate resuscitative procedures there was no spontaneous respiration and the patient required endotracheal intubation.

Address for reprint requests: Dr Carmen Navarro, Neuropatologia Hospital Infantil, CS Valle de Hebrón, Barcelona-08035, Spain.

Received 1 December 1987 and in revised form 5 March 1988. Accepted 19 March 1988
On admission to the newborn intensive care unit, physical examination revealed marked hypotonia, absent deep tendon reflexes in the four limbs, and lack of spontaneous movment and respiration. No malformations or neurocutaneous stigmata were observed. No masses, liver or spleen enlargement were felt on palpation. There was no family history of neuromuscular disorders, retinal disease or tumours in the cerebellum or spinal cord. Chest radiography and routine laboratory tests were normal after a period of adjustment to mechanical ventilation. Cerebrospinal fluid contained 450 red blood cells with $0.97 \mathrm{~g} / \mathrm{l}$ of protein and $0.73 \mathrm{~g} / \mathrm{l}$ of glucose. Seven hours after admission she developed tension pneumothorax. After surgical drainage, persistence of fetal circulation syndrome was detected, requiring sedation and curare administration. Cerebral transfontanelle ultrasound study performed a few hours later was normal.

One week later, after curare and sedatives had been discontinued and the patient's circulatory complications had improved, neurological examination remained unchanged. Facial movements were normal. Sucking was present and strong. Pupil reactions and passive ocular movements were normal. No tongue fasciculations were noted. The patient consistently responded with a facial grimace or cry to pinpricks to the neck. She adopted a frog-like position and no movement of the trunk and limbs could be elicited even with sustained deep or superficial painful stimulation. Manual pressure on the bladder (Crede's manoeuvre) provoked dribbling of urine and decreased tone of anal sphincter. Myelogram followed by a CT scan with sagittal cuts showed no spinal cord pathology. Electromyography, nerve conduction velocities and muscle biopsy were normal.

Three weeks after birth, no changes were observed on neurological examination. Somatosensory evoked potentials obtained by stimulation of both medial nerves at the wrist showed normal Erb point response on both sides; the early cervical response was of low amplitude on the right and the remaining cervical and cortical responses were not obtain- 


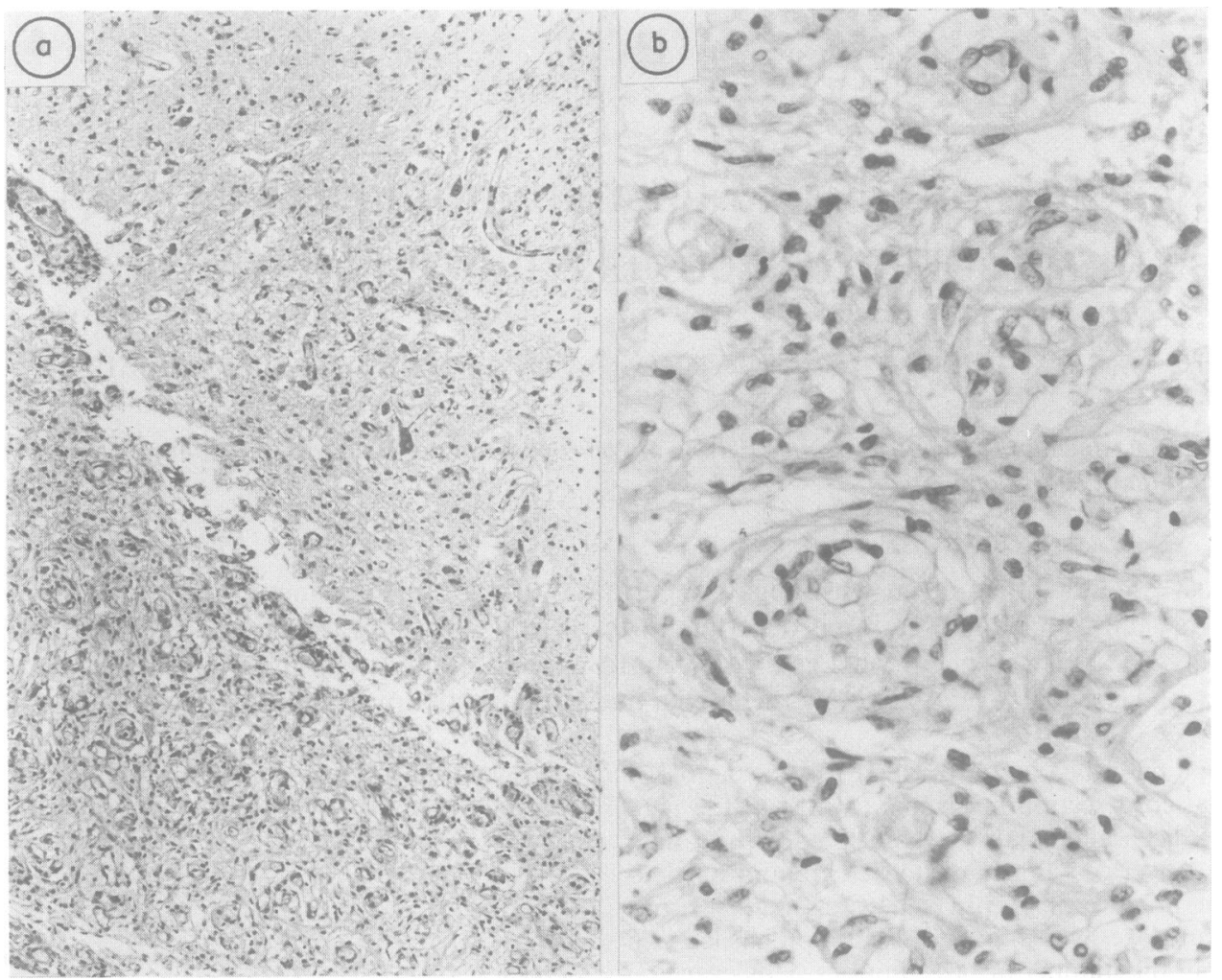

Fig (a) Tumour tissue invading the spinal cord. Note several anterior horn motor neurons on the left. (HE $\times 140)$. (b) Section of the haemangioblastoma, composed of thin-walled capillaries, large endothelial cell nuclei and foamy cells. $(\mathrm{HE} \times 555)$.

able. A second myelogram revealed no spinal cord abnormality. The patient died at 6 weeks of age from cardio-respiratory complications.

\section{Pathological findings}

Post-mortem study revealed bacterial bronchopneumonia and sepsis as the cause of death. Macroscopic examination of the brain, brain stem and cerebellum was unremarkable. The spinal cord had a regular diameter at all levels. After sectioning, a striking yellow discoloration of the cervical cord with diminished consistency was observed. Transverse sections from different levels of the spinal cord were embedded in paraffin wax and stained with Haematoxylin Eosin (HE), Periodic Acid Schiff (PAS), Woelcke, Mallory, and Wilder's technique for reticulin fibres. In addition, frozen sections of the cervical level were stained with $\mathrm{HE}$ and Oil red $\mathbf{O}$. Histology showed a tumour like vascular tissue, totally invading the cord at the upper cervical levels $(\mathrm{C} 1-\mathrm{C} 2)$. The abnormal tissue surrounded and infiltrated the spinal structures irregularly as far as C5 (fig a). The neoplastic tissue was composed of capillaries with swollen endothelial cells. Vascular lumina were separated by abundant stromal foamy cells, which showed large numbers of sudanophilic lipid droplets on frozen sections (fig b). Wilder's technique demonstrated an extensive network of reticulin fibres outlining the vascular architecture. The pathological diagnosis was congenital capillary haemangioblastoma of the spinal cord. No pathological manifestations of von Hippel-Lindau disease were found.

\section{Discussion}

Differential diagnosis of SCSS in the newborn includes neuromuscular diseases such as the infantile form of spinal muscular atrophy (Werdnig Hoffmann disease) infantile form of type II glycogenosis (Pompe's disease), cleft spinal cord, transversal myelitis and intra medullary tumours. ${ }^{6}$ Aetiology is difficult to assess since many patients with this syndrome die during the first hours of life, and post mortem study including the spinal cord is not always carried out.

Two different syndromes emerge from a review of more than 200 published cases: ${ }^{7-9}$ (1) cervicothoracic section syndrome, generally associated with breech delivery and (2) upper cervical section syndrome, usually related to cephalic delivery with 
hyperextension of the neck. The former is characterised by flaccid weakness and arreflexia in the lower limbs, with varying degrees of upper limb involvement and frequent Thorburn posture (arms held in strong abduction at the shoulders, with flexion at the elbows and wrists); sensory level is in the upper trunk. Sphincters are involved and there is paradoxical breathing. In the second syndrome, physical examination reveals flaccid tetraplegia with arreflexia, lack of spontaneous respiration and neck pin-prick sensory level. Facial and extraocular movements are spared.

Upper cervical spinal cord section was diagnosed in our patient five days after birth, when curare was discontinued. Cephalic delivery, negative neuroradiologic findings and lack of perinatal trauma, made trauma an unlikely cause. However, sparing of the facial and extraocular muscles, absence of tongue fasciculations, normal nerve conduction velocities, normal muscle biopsy and the detection of a conduction block by somatosensory evoked responses ruled out other diagnoses.

Myelography is the method of choice in the diagnosis of spinal cord lesions. Magnetic resonance imaging ${ }^{10}$ could not be performed in our patient owing to her clinical condition. However, it was possible to obtain direct sagittal cuts on CT scan, a procedure which may be helpful and complementary after myelography in the newborn. Somatosensory evoked responses as in the case published by Bell, ${ }^{11}$ were helpful in demonstrating a conduction block at cervical level, since neuroradiological studies were negative.

Congenital central nervous system tumours are rare and are mainly gliomas or teratomas, followed by meningeal tumours, neuroblastomas and medulloblastomas. ${ }^{12}$ The finding of a congenital spinal capillary haemangioblastoma is exceptional.

This tumour is usually located in the cerebellum and occurs mainly in young and middle-aged adults. A spinal cord location is second in frequency followed by the medulla and some exceptional supratentorial cases. ${ }^{13-15}$ It can be associated with other lesions or tumours as in von Hippel-Lindau disease, and family incidence has been reported in a high percentage of cases. $^{16-18}$

To our knowledge, congenital intracranial haemangioblastoma has only been reported once, ${ }^{19}$ and from all the published cases of spinal cord haemangioblastoma none was encountered in neonates. ${ }^{20} 21$

We are grateful to Drs M Rovira and F J Romero for the neuroradiological studies, to Dr C Ruiz de Miguel who performed the general post-mortem examination, to $\mathrm{Dr} \mathrm{M}$ Olesti for the neurophysiological examinations and to Miss Christine O'Hara for improvement of English style in the manuscript.

\section{References}

1 Parrot MJ. Note sur un cas de rupture de la moelle chez un nouveau-né, par suite de manoeuvres pendant l'accouchement. Bull Mem Soc Med Paris 1869;6:38-45.

2 Pierson RN. Spinal and cranial injuries of the baby in breech deliveries. Surg Gynecol Obstet 1923;37:802-15.

3 Towbin A. Latent spinal cord and brain stem injury in newborn infants. Dev Med Child Neurol 1969;2:54-68.

4 Bresnan MJ, Abroms IF. Neonatal spinal cord transection secondary to intrauterine hyperextension of the neck in breech presentation. J Pediatr 1974;84:734-7.

5 Maekawa K, Masaki T, Kokubun Y. Fetal spinal cord injury secondary to hyperextension of the neck: no effect of caesarean section. Dev Med Child Neurol 1976:229-32.

6 Allen JP. Birth injury to spinal cord. Northwest Med 1970;69:323-6.

7 Bucher HU, Boltshauser E, Friderich J, Isler W. Birth injury to the spinal cord. Helv Paediat Acta 1979;34:517-27.

8 Volpe JJ. Neurology of the Newborn. Philadelphia: WB Saunders, 1987:645-8.

9 Enriquez G, Aso C, Lucaya J, Creixell S, Fernandez E. Traumatic cord lesions in the newborn infant. Ann Radiol 1976;19:179-86.

10 Packer RJ, Zimmerman RA, Sutton LN, Bilaniuk LT, Bruce DA, Schut L. Magnetic Resonance Imaging of Spinal Cord Disease of Childhood. Pediatrics 1986;78:251-6.

11 Bell HJ, Dykstra DD. Somatosensory evoked potentials as an adjunct to diagnosis of neonatal spinal cord injury. $J$ Pediatr 1985;106:298-301.

12 Solitare GB, Krigman MR. Congenital intracranial neoplasm: a case report and review of the literature. J Neuropathol Exp Neurol 1964;23:280-92.

13 Diehl PR, Symon L. Supratentorial intraventricular hemangioblastoma: case report and review of literature. Surg Neurol 1981;15:435-43.

14 Romero FJ, Rovira M, Ortega A. Computed tomography in supratentorial hemangioblastoma. Comput Radiol 1984;8: 319-23.

15 Rubinstein LJ. Tumors of the CNS. Washington DC: Armed Forces Institute of Pathology. 1972:235-40.

16 Fabiani A, Favero M, Delsedime M, Durelli L, Brignolio F, Benech F. On the familial occurrence of solitary cerebellar hemangioblastomas: a clinicopathological study of a family with four affected members. Acta Neurol Belg 1982;82:317-26.

17 Horton WA, Wang V, Eldridge R. Von Hippel-Lindau disease: clinical and pathological manifestations in nine families with 50 affected members. Arch Intern Med 1976;136:769-77.

18 Lindau A. Studien uber Kleinhirncysten: Bau, pathogenese und beziehungen zur angiomatosis retinae. Acta Pathol Microbiol Scand 1926;3 (suppl 1): 1-128.

19 Bergstrand H, Olivecrona H, Tonnis W. Gefassmissbildungen und Gefassgeschwulste des Gehirns. Leipzig: Thieme, 1936:181.

20 Browne TR, Adams R. Haemangioblastoma of the spinal cord. Review and report of five cases. Arch Neurol 1976;33:435-41.

21 Sandford RA, Smith RA. Hemangioblastoma of the cervicomedullary junction. Report of three cases. $J$ Neurosurg 1986;64:317-21. 